\section{Perceived information needs and effect of symptoms on activities after surgery for lung cancer}

\author{
By Susan C. Galloway, Natalie Bubela, \\ Ann McKibbon, Elizabeth McCay, and Eleanor Ross
}

\section{Abstract}

Forty participants who had an open thoracotomy for primary lung cancer were interviewed to determine what information they perceived as being important and what effect selected symptoms had on usual activities prior to and after discharge. Discharge information needs were measured on the 50-item Patient Learning Need Scale (PLNS). The effect of selected symptoms on usual activities was measured on visual analogue scales. The PLNS subscales of Treatment and Complications and Enhancing Quality of Life were identified as being of high importance both prior to and after hospital discharge. Fatigue and pain were the symptoms which had the most effect on the ability to perform usual activities prior to and after hospital discharge. These findings can assist murses in targeting relevant mursing interventions.

\section{Introduction}

Cancer of the lung is the most common type of cancer in men and the third most common type of cancer in women (National Cancer Institute, 1992). Treatment by surgical resection is the most effective therapy for non-small cell lung cancer but, even with surgery, five-year survival rates are only $35 \%$ to $40 \%$ (Shields, 1993). Individuals with lung cancer treated by surgery begin adjustment in the hospital to their changed life. To cope with this new life situation most individuals will seek information to increase their understanding of illness-related events. Accurate, relevant information can assist individuals in both emotional-regulating and problem-solving functions associated with their cancer experience (Lazarus \& Folkman, 1984). Information may become increasingly important at the time of hospital discharge as individuals adapt to their diagnosis of lung caneer and become more independent in the management of their treatment-induced symptoms.

Surgical oncology nurses are in a position to provide information to individuals being treated for lung cancer. After surgery, these individuals may have neither the physiological stability nor the cognitive energy to seek or comprehend information, and it may not be until near the time of hospital discharge that they are ready to formulate questions or understand information provided. With shorter hospital stays, time constraints on patient education increase and nurses may fail to ask what type of discharge information the individual needs and focus on giving information that the health care providers believe is important. The incongruencies in the importance of information needs as perceived by individuals with cancer and health care providers have been demonstrated (Lauer, Murphy \& Powers, 1982; Pfefferbaum \& Levenson, 1982) and may lead to finstration and to misuse of limited time available for teaching.

Early recognition and attention to information needs could improve the quality of life during recovery following lung cancer surgery.
Appropriate information may enhance individuals' understanding of illness-related events and management of treatment-induced symptoms. Unfortunately, there was little empirical knowledge about specific discharge information needs after surgery for lung cancer and there was no documentation about whether the importance placed on these information needs changed after transition from hospital to home. Therefore, the purpose of this investigation was to examine information needs and the effect of symptoms on activities of individuals after surgery for lung cancer prior to and after hospital discharge.

\section{Background information}

The importance of information to early post-discharge outcomes after lung surgery has been examined in only one study. Individuals who were given instruction demonstrated greater knowledge and adherence to some but not all activity suggestions when compared to individuals with no instruction (Goodwin, 1979). The specific instructions utilized were not explained. There were no differences between individuals who had or had not received instructions on most of the distress measures or plans to resume work. Individuals diagnosed with other types of cancer have identified that knowledge about disease, treatment, medications, personal activities and social relationships are important information needs (Bubela et al., 1990b, Derdiarian, 1986). Consistent differences in information needs on the basis of age, gender or stage of disease have not been identified.

Regardless of the type of treatment, there is evidence that the experience of lung cancer is associated with human suffering. Benedict's (1989) descriptive study of 30 lung cancer patients demonstrated that $50 \%$ of the sample reported the highest level of suffering possible measured on a five-point likert scale. The suffering associated with the physical aspects of lung cancer was greater than the suffering associated with the psychological aspects. Individuals with a new diagnosis of lung cancer report more concerns than other cancer groups (Weisman \& Worden, 1976). During tratment by chemotherapy or radiotherapy, these individuals report high

\section{PERCEPTION DES BESOINS EN MATIĖRE D'INFORMATION ET EFFETS DES SYMPTÔMES SUR LES ACTIVITÉS APRĖS UNE OPÉRATION D'UN CANCER DU POUMON}

\section{ABRÉGÉ}

On a interviewé quarante participants ayant subi une thoracotomic à la suite d'un cancer primitif du poumon afin de déterminer quelle était, selon eux, l'information importante avant et après leur sortic de l'hôpital et pour savoir quel effet les symptômes choisis avaient sur leurs activités habituelles. Les besoins d'information à la sortie ont été mesurés à l'aide de l'échelle à 50 points "Patient Learning Need Scale" (PNLS).

L'effet des symptômes choisis sur les activités habituelles était mesuré sur des échelles visuelles analogues. Les sous-catégories de l'échelle PNLS "Traitement et Complications" et "Amélioration de la qualité de vie" ont reçu la mention "très important" ả la fois avant et après la sortie de l'hôpital. La fatigue et la douleur étaient les symptômes qui affectaient le plus la capacité des patients à effectuer leurs activités habituelles ả la fois avant et après la sortie de l'hôpital. Ces résultats peuvent aider les infirmières à prendre pour cible des interventions infirmières appropriées.

Susan C. Galloway, RN, MScN, is a clinical nurse specialist at Sunnybrook Health Science Centre, Toronto, Ontario. Natalie Bubela, RN, MSc (A), is director of nursing services at Scarborough Grace Hospital, Scarborough, Ontario. Ann McKibbon, RN, BScN, is a nursing unit director at Sunnybrook Health Science Centre. Elizabeth McCay, RN, MScN, is a clinical nurse specialist at the Clarke Institute of Psychiatry, Toronto, Ontario. Eleanor Ross, RN, MScN, is chief of nursing practice at Women's College Hospital, Toronto, Ontario. 
symptom distress scores one and two months after diagnosis (Germino \& McCorkle, 1985). Concerns at three and six months post-diagnosis were related to symptoms (Driever \& MoCorkle, 1984). Symptoms identified as most distressing by individuals with inoperable lung cancer treated by radiotherapy (Kukull, McCorkle \& Driever, 1986) and women who had a diagnosis of lung cancer for more than one year (Sama, 1993) were fatigue, pain, appetite problems, coughing and insomnia. It was not known whether the symptoms of individuals with inoperable or recurrent lung cancer were similar to individuals after surgical treatment.

In summary, individuals with a recent diagnosis of lung cancer felt distressed regardless of the treatment modality. Receiving accurate information was identified as being important to individuals with cancer, but the specific type of information desired after surgery for lung cancer was not clear. Illness-related symptoms were identified as important factors to examine in an illness experience, but it was unknown whether symptoms were associated with information needs of individuals with lung cancer. Therefore, the objectives of the study were: (1) to examine the information needs and the effect of symptoms on activities in individuals with lung cancer treated by surgery prior to and two to four weeks after hospital discharge and (2) to identify the relationship between information needs and the eflect of symptoms on activities.

\section{Methodology}

Data in this study represent a portion of data collected in a larger study of mood, performance status, physical symptoms and information needs of individuals with lung cancer (Galloway, et al., 1993). The study protocol was approved by each institutional committee on human research and informed written consent was obtained from each subject. Forty individuals who had open thoracotomy for primary lung cancer in an 18-month period in three urban teaching hospitals in Canada comprised the convenience sample. Twelve potential subjects were lost due to refusal to participate or early hospital discharge. All subjects knew their diagnosis, were mentally competent as judged by their nurse, English speaking and willing to participate in the study. Thirty-three subjects completed the second interview. The seven post-discharge interviews not done were due to refusal (6), or inability to contact (1). Each subject was interviewed 48 to 72 hours prior to hospital discharge, four to 112 days post-operatively (mean=13.5). Post-discharge interviews oocurred eight to 65 days after hospital discharge (mean $=24.5$ ) at home or on retum to clinic.

\section{Instruments}

Discharge information needs were measured on the Patient Learning Need Scale (PLNS) a 50-item self-report scale of the perception of the importance of learning needs related to self-management of health care after hospital discharge (Bubela et al., 1990a). In the hospital, subjects were asked to rate how important an item was to learn before going home. At home, subjects were asked how important the item was to learn before discharge to resume management of care once home. Each item was scored on a scale of 0 (does not apply) to 5 (extremely important). The scale yielded a total score and seven subscale scores. Subscale titles and examples of the type of information need in these subscales are seen in Table One. Content validity was established from a review of the literature and beginning construct validity was established from a factor analytic study utilizing 301 medical and surgical patients approaching hospital discharge (Bubela, et al., 1990b). In this study, the internal consistency reliabilities pre and post-discharge were .97 for the total PLNS score and .80 to .90 for the subscales.

Perception of the effect symptoms had on the ability to carry out activities was measured on visual analogue scales. The symptoms examined were: loss of appetite, cough, fatigue, pain and breathlessness (dyspnea). The visual analogues were based on previously developed scales (Boyd, et al., 1988) which had reported concurrent validity with the Sickness Illness Profile, and the Karnofsky Scale of Performance Status (Selby et al., 1984). Each symptom was represented by a title and a $100 \mathrm{~mm}$ visual analogue scale. Subjects placed a vertical mark on each scale in a position that described the symptom's effect on their usual activities during the previous 24 hours. Responses were scored by assigning a value of 0 to the end of the seale representing no effect and 100 to the opposite end. Higher scores represented more severe impairment of activities.

\section{Results \\ Sample}

There were 18 females and 22 males whose ages ranged from 42 to 81 with a mean age of 63 . The majonity of subjects were either married $(65 \%)$ or widowed $(17.5 \%)$. Level of education ranged from grade school to graduate school. Due to the small numbers, the sample was dichotomized on the basis of education to a high education group of 16 subjects representing community college and university, and a low education group of 24 subjects representing grades 6 to 13. Surgical intervention was lobectomy $(n=30)$, pncumonectomy $(n=6)$, or wedge resection $(n=4)$. Length of hospitalization ranged from seven to 120 days $(\operatorname{mean}=21$, sd 20).

\section{Effect of symptoms on activities}

Symptom scores were in the moderate range pre-discharge and decreased during the early recovery period at home. As shown in Table Two, fatigue and pain were the symptoms which most affected ability to do usual activities prior to and after hospital discharge. Pre-discharge fatigue was positively correlated to both breathlessness $(\mathrm{r}=.34, \mathrm{p}=.03)$ and loss of appetite $(\mathrm{r}=.54, \mathrm{R}=.003)$. Two to four weeks following discharge, it was observed that fatigue was not significantly associated with either breathlessness or loss of appetite, but pain was associated with cough $(\mathrm{r}=.56, \mathrm{p}=.0007)$, breathlessness $(\mathrm{r}=.53, \mathrm{p}=.001)$, loss of appetite $(r=35, p=.05)$ and fatigue $(r=.40, p=.02)$.

\section{Discharge information needs}

Before hospital discharge, subjects expressed a high number of information needs (mean $=179.2, \underline{\mathrm{sd}}=50.1$ ) related to resumption of self-care. There were no differences in overall mean scores on the basis of gender or education group as determined by the t-test. Length of time hospitalized was not significantly correlated to the overall PLNS scores. PLNS subscales were composed of an unequal number of questions and

\section{Table One: PLNS subscale labels ${ }^{\mathrm{a}}$ and examples}

\section{Subscale label}

Medication

Activities of living

Community \& follow-up

Feelings about condition

Treatment \& complications Treatment purpose and side effects, recognizing and managing complications

Enhancing quality of life Impact of illness on present and future

Skin care

Note: ${ }^{a}$ Bubela et al., (1990b)

Table Two: Measures of central tendency of effect of symptoms on activity scales Pre-discharge $(n=40)$ and Post-discharge $(n=33)$

\begin{tabular}{lllll} 
Symptom & \multicolumn{2}{c}{ Pre-discharge } & \multicolumn{2}{c}{ Post-discharge } \\
& Mean & sd & Mean & sd \\
Cough & 28.1 & 35 & 21.4 & 28 \\
Difficult Breathing & 44.6 & 34 & 33.6 & 28 \\
Fatigue & 64.0 & 30 & 56.4 & 28 \\
Loss of Appetite & 46.7 & 37 & 31.0 & 28 \\
Pain & 58.1 & 35 & 36.5 & 27
\end{tabular}


Table Three: Percentage mean PLNS subscale scores pre-discharge $(n=39)$ and post-discharge $(n=33)$

\begin{tabular}{lcc} 
& \multicolumn{3}{c}{ Mean (\%) } \\
Subscales & Pre-discharge & Post-discharge \\
Medication & 71 & 68 \\
Activities of living & 70 & 66 \\
Community and follow-up & 65 & 54 \\
Feelings about condition & 68 & 64 \\
Treatment \& complications & 82 & 73 \\
Enhancing quality of life & 78 & 72 \\
Skin care & 72 & 56
\end{tabular}

Table Four: Highest mean scored information items on PLNS before discharge home $(n=39)$

In order to manage care

at home I need to know

1. How to recognize

a complication

2. How to prevent a complication

3. Which complication I should

seek immediate help for

4. What complications might occur from my illness

5. What physical exercise I should get

6. Who will I see on return to clinic

$\begin{array}{lll}\text { Mean } & \text { sd } & \text { range } \\ 4.50 & 1.2 & 0-5 \\ 4.30 & 1.2 & 0-5 \\ 4.32 & 1.2 & 0-5 \\ 4.28 & 1.4 & 0-5 \\ 4.23 & 1.1 & 0-5 \\ 4.21 & 1.4 & 0-5 \\ 4.08 & 1.5 & 0-5 \\ 4.07 & 1.4 & 0-5 \\ 4.02 & 1.8 & 0-5 \\ 4.02 & 1.5 & 0-5\end{array}$

7. What the possible side effects of my treatment are

8. How this illness will affect my future

9. How to care for my wound or incision

10. How this illness will affect my life

Table Five: Highest mean scored information items on PLNS once home $(n=33)$

In order to manage care

at home I need to know:

$\begin{array}{lll}\text { Mean } & s d & \text { Range } \\ 4.4 & 1.1 & 1-5 \\ 4.1 & 1.1 & 1-5 \\ 4.1 & 1.3 & 1-5 \\ 4.1 & 1.1 & 1-5 \\ 4.0 & 1.4 & 0-5 \\ 4.0 & 1.2 & 1-5 \\ 3.9 & 1.6 & 0-5 \\ 3.9 & 1.6 & 0-5 \\ 3.8 & 1.4 & 0-5 \\ 3.1 & 1.8 & 0-5\end{array}$

to identify the areas of greatest information need, percentage means for subscale scores were calculated (see Table Three). Pre-discharge subjects reported high importance of information needs in the subscales of Treatment and Complications and Enhancing Quality of Life.

Specific information needs were explored by identifying 10 items on the PLNS with the highest mean scores pre-discharge (see Table Four). The four most important items indicated that individuals wanted information to help them prevent, recognize and make judgments about complications. Information about activity guidelines, incisional care, and how their lung cancer illness would impact on present and future life were felt to be very important in order to manage care at home.

\section{Discharge information needs as judged once home}

At the home interview, subjects were given the community version of the PLNS which asked how important it would be to know about an item before discharge to manage at home. The total scores ranged from 46 to 240 in a possible range of 0 to 250 (mean $=164.3, \mathrm{sd}=52.7$ ). Subscale scores were converted to mean percentages (see Table Three) and the subscales of Treatment and Complications and Enhancing Quality of Life remained the two most important areas of information need. The 10 discharge information needs with the highest mean scores identified after subjects were home are outlined in Table Five. Congruent with the pre-discharge interview, information about complications, activity guidelines and illness impact were among the highest mean item scores. Additionally, information about illness-related symptoms, symptom management and reactions to medications were identified as important. Thus, the importance of information about symptoms increased in relation to other types of information from the pre-discharge to the post-discharge interview.

\section{Discharge information needs before and after hospital discharge}

Subjects were asked to identify the importance of discharge information needs prospectively prior to leaving the hospital and again after being at home. There was a significant decrease in the importance placed on discharge learning needs once subjects had been at home for several weeks $(t=2.13, p=.04)$. There was a significant decrease in the mean subscale scores of Treatment and Complications, Enhancing Quality of Life and Skin Care. The decrease was not significant in the subscales of Medications, Activities of Living, Feelings Related to Condition, and Community and Follow-up.

\section{Effect of symptoms and discharge information needs}

Prior to hospital discharge, pain was the only symptom which was positively correlated to information needs as measured by the PLNS score $(\mathrm{r}=35, \mathrm{p}=.03)$. The positive correlation of the effect of pain was identified with the subscales of Medications $(\mathrm{r}=.39, \mathrm{p}=.01)$, Feelings Related to Condition $(\mathrm{r}=41, \mathrm{p}=.01)$, Treatment and Complications $(\mathrm{r}=.37, \mathrm{p}=.02)$ and Enhancing Quality of Life $(r=.34, p=.03)$. At the discharge interview, subjects' retrospective perceptions of their discharge information nceds were not associated to any symptom measured.

\section{Discussion}

Individuals after lung surgery for cancer felt a moderately high amount of information was needed to help them manage after hospital discharge. The moderately high levels of importance placed on information at the time of hospital discharge is compatible with Lazarus and Folkman's (1984) postulation that when facing a new situation, individuals seek information to help them cope. The information may enable the individual to objectively interpret an event when it occurs and institute effective coping behaviour. Neither age nor level of education was associated with importance placed on discharge information needs, thus nurses cannot assume that an individual's age or level of education will impact on the importance placed on discharge information. After lung surgery, individuals reported that information about their treatment, possible complications, managing symptoms, and medications was highly important. These areas of importance remained consistent after discharge, emphasizing that individuals were able to predict their need for information related to their recovery.

Surgical treatment for lung cancer does not ensure survival and 
individuals were realistically concemed about the impact of illness on their life at present and in the future. They desired specific information about how to recognize and manage both complications and treatment-induced symptoms. This type of information could be used to plan actions to decrease the negative impact of their illness on their life. The importance placed on information to help understand and manage symptoms may also be a reflection of the high level of negative effect which symptoms such as fatigue and pain had on activities just 24 to 48 hours prior to discharge.

Fatigue was the symptom with the greatest impact on usual activities both prior to and after hospital discharge. Fatigue may interfere with resumption of usual activities for up to 30 days after uncomplicated surgical procedures and longer periods of time after more complex operations (Rose \& King, 1978). The fatigue reported by individuals following lung cancer surgery would be an expected post-operative symptom pre-discharge and during the recovery period. In this study, fatigue was significantly positively correlated to both breathlessness and loss of appetite. Breathlessness was a moderate problem for individuals and could be due to surgical loss of tissue, especially if pre-existing respiratory disease was present. It could not be determined if breathlessness contributed to fatigue, or if the fatigue contributed to breathlessness.

Pain was a major problem interfering with ability to pursue usual activities. The more pain individuals had before discharge, the more importance they placed on information to help them manage once home. Increased pain may heighten the threat of impending discharge and increase the importance of information to an individual. Pain may also interfere with the ability to direct attention to important information in the environment (Cimprich, 1992) and decrease the comprehension of information given. If pain was seen as a complication, the immediacy of the experienced sensation could account for the high level of importance placed on information related to the recognition, prevention and treatment of complications.

\section{Implications for nursing practice}

Individuals anticipating hospital discharge after surgical resection for lung cancer have many information needs. Informing individuals about actions to take if complications such as increasing breathlessness, fever, and/or change in sputum production occur may help problem-solving in the early recovery period. Reviewing specific self care activities such as medication taking, desired activity levels and nutritional intake may also optimize patient functioning. Nurses attending to these needs through the provision of information may facilitate the resumption of self care, reduce individual risk and enhance individual understanding of the illness experience.

Attention should be given to educating individuals about the management of fatigue, pain and breathlessness. Therapeutic goals for fatigue could include prevention, minimization and evaluation of intervention effectiveness. Information which may be useful in assisting individuals to manage fatigue include the benefits of a daily activity-rest program, maintenance of an adequate intake of nutrients and involvement in activities designed to stimulate thought processes. Each individual must be actively involved in determining efficacy, for what may be helpful for one may not be for another.

Pain requires careful attention, with the ultimate goal being to increase ability to engage in usual activities with little or no pain. Both pharmacological and nonpharmacological approaches to pain management could be implemented based on a careful biopsychosocial assessment. Individuals can be given information about their pain, encouraged to communicate possible fears and taught how to actually manage their pain This may involve suggestions about the amount and timing of analgesics and altemative interventions such as relaxation and distraction. Therapeutic goals in treating breathlessness could include increasing the felt ease of breathing, increasing exercise tolerance and decreasing tiredness. Information about planning an incremental exercise regimen, controlling pain, and encouraging deep breathing and coughing may assist individuals in achieving a reduction in breathlessness.

In conclusion, the identification of information needs perceived to be important and the provision of relevant information are crucial to the successful bolstering of individuals after surgical resection of primary lung cancer. Surgical oncology nurses are strategically positioned to assist individuals in meeting these information needs, thereby facilitating a smoother transition from hospital to home and enhancing quality of life in the recovery period.

\section{Acknowledgements}

This research project was funded by the Canadian Lung Association/Canadian Nurses Respiratory Society

\section{References}

1. Benedict, S, (1989). The suffering associated with lung cancer. Cancer Nursing, 12, 34-40.

2. Boyd, N.F., Selby, P.J., Sutherland, H.J., \& Hogg, S. (1988). Measurement of the clinical status of patients with breast cancer: Evidence for the validity of self-assessment with linear analogue scales. Joumal of Clinical Epidemiology, 41, 243-250.

3. Bubela, N., Galloway, S.C., McCay, E., McKibbon, A., Nagle, L., Pringle, D., Ross, E., Shamian, J. (1990)a. Factors influencing patients' learning needs at time of hospital discharge. Patient Education and Counseling, 16, 21-28.

4. Bubela, N., Galloway, S.C., McCay, E, McKibbon, A., Nagle, L., Pringle, D., Ross, E., Shamian, J. (1990)b. Patient learning needs scale: Reliability and validity. Joumal of Advaneed Nursing, 15, 1181-1187.

5. Cimprich, B., (1992). A theoretical perspective on attention and patient education. Advances in Nursing Science, 14, 39-51.

6. Derdiarian, A.K. (1986). Informational needs of recently diagnosed cancer patients. Nursing Research, 35, 278-281

7. Driever, M.J. \& McCorkle, R. (1984). Patient concems at 3 and 6 months postdiagnosis. Cancer Nursing, 7, 235-241

8. Galloway, S.C., Bubela, N., McCay, E., McKibbon, A.\& Ross, E. (1993). Surgically treated lung cancer patients' information needs at hospital discharge. Unpublished manuscript, Sunnybrook Health Science Centre, North York, Ontario

9. Germino, B. \& McCorkle, R. (1985). Acknowledged awareness of life threatening illness. Intemational Journal of Nursing Studies, 22, 33-44. 10. Goodwin, J.O. (1979). Programmed instruction for self-care following pulmonary surgery. International Journal of Nursing Studies, 16, 29-40. 11. Kukull, W.A., McCorkle, R., \& Driever, M. (1986). Symptom distress, psychosocial variables and survival from lung cancer. Journal of Psychosocial Oncology, 4, 91-104.

12. Lauer, P., Murphy, S., \& Powers, M.J. (1982). Learning needs of cancer patients: A comparison of nurse and patient perceptions. Nursing Research, 31, 11-16.

13. Lazarus, R.S. \& Folkman, S. (1984). Stress, appraisal and coping. New York: Springer.

14. National Cancer Institute (1992), Canadian Cancer Statistics. Toronto: National Cancer Institute of Canada.

15. Pfefferbaum, B. \& Levenson, P. (1982). Adolescent cancer patient and physician response to a questionnaire on patient concerns. American Joumal of Psychiatry, 139, 348-351.

16. Rose, E.A., \& King, T.C. (1978). Understanding postoperative fatigue. Surgery, Gynaecology and Obstetrics, 147, 97-102.

17. Sama, L. (1993). Correlates of symptom distress in women with lung cancer. Cancer Practice, 1, 21-28.

18. Selby, P.J., Chapman, J.A.W, Etazadi-Amoli, J., Dalley, D. \& Boyd, N.F. (1984). The development of a method for assessing the quality of life of cancer patients. British Journal of Cancer, 50, $13-22$.

19. Shields, T.W. (1993). Surgical therapy for carcinoma of the lung. Clinies in Chest Medicine, 14, 121-147.

20. Weisman, A.D. \& Worden, J.W. (1976). The existential plight in cancer: Significance of the first 100 days. International Journal of Psychiatry in Medicine, 7, 1-15. 